ACTA SCIENTIFIC NUTRITIONAL HEALTH (ISSN: 2582-1423)

Volume 3 Issue 8 August 2019

Short Communication

\title{
Top 6 Tips for Muscle Growth
}

\section{Mary-Adelle Smith*}

Dietitian and Nutritionist, Kelvin Grove Bc, Queensland, Australia

*Corresponding Author: Mary-Adelle Smith, Dietitian and Nutritionist, Kelvin Grove Bc, Queensland, Australia.

Received: July 04, 2019; Published: July 31, 2019

DOI: 10.31080/ASNH.2019.03.0390

Sleep

Sleep often gets overlooked as an important factor in gaining muscle mass. It is drilled into us as kids because we're growing we are told to sleep, and as we approach adolescence the desire to stay up watching Netflix, scrolling through the 'gram' or getting knee deep into videos on YouTube often outweighs our or our own desires to be "healthy". Or maybe that's just me!

When you sleep your body typically releases growth hormone, one of the main hormones involved in muscle recovery and growth. Not getting enough sleep also means less energy for training. Anyone struggling with getting to sleep, could benefit from finding a night time routine that works for you. Some strategies I find useful include; meditation, turning off electronics, dimming the lights, baths, journaling, massage, avoiding alcohol, essential oils and night yoga.

Studies have shown that sleeping allows the brain to remove harmful metabolites [1]. Accumulation of these metabolites have now been linked to cognitive decline and Alzheimer's disease [2]. Basically, sleeping assists the brain to reset and think with more clarity the next day. Overtime, meditation and sleep will also help to prevent excessive levels of cortisol. Meditation reduces resting heart rate and overall stress in people who practice mediation regularly. Cortisol is known as the "stress hormone" which is vital in everyday life. The release of cortisol is what helps you to wake up in the morning, exercise and respond to stressors in everyday life. Undesirable weight loss, lower recovery, increased soreness and overall reduced energy/fatigue has been shown in individuals with prolonged levels of cortisol. Elevated cortisol over time also causes insulin resistance. Insulin allows the food that has been converted into glucose (sugar) to be taken up by the body's tissues. Too much insulin however, causes reduced sensitivity to insulin which for muscle growth means uptake of glucose into muscles is lowered because the glucose is circulating around the body in "fight or flight" (no longer responding or responding less to insulin). Less growth hormone is also released in response to insulin.

Training stimulus

To gain muscle it is imperative that you have some sort of stimulus. Whether it be gym, yoga, sport etc., there has to be some stress to the muscle that will cause growth. Basically, you need to shock your body in a way again and again to cause an "adaptation". Studies by **have shown microtears etc.... All exercise has substantial mental and physical benefits to say the least, however those serious about gaining muscle mass should see a qualified exercise scientist, physiologist or PT to go through a hypertrophy program. For anyone unfamiliar with the term hypertrophy, it means 'gains' pretty much.

Goals directed towards gaining muscle size will typically involve a training program with a higher volume of reps compared to those with goals to increase strength and power. Hypertrophy programs generally include working the muscles you want to grow 2-3 times per week with 36-48hrs recovery in between. Even if you have been training hypertrophy it may be a good idea to mix it up and work on strength, power or even endurance so that you don't get stuck in a counterproductive hypertrophy phase. I'm not qualified to give too much advice about training, but I can recommend some excellent health professionals who have helped me with my own fitness journey!

\section{Energy surplus}

This one can be the hardest or the easiest step of all depending on what type of client you are. The consensus based on *study/sys review* is that $0.5 \mathrm{~kg}-1 \mathrm{~kg}$ gain per week is ideal (especially if you 
don't want to gain fat mass). To gain this much most people need to eat an extra 500-1000 calories than what they burn throughout the day. Working out what you burn in a day is significantly easy to under or over estimate so make sure you work with a qualified health professional to work this out, or at least try to factor in age, sex, height, weight, metabolism, physical activity if you use an online estimator. There's also a thermic effect of food which means your body heat rises and burns more calories while you digest food so the more you eat and digest the more calories you burn. Thermic effect of food only accounts for about $10 \%$ of overall calories burned so don't use it as an excuse to keep eating when you don't need to. As you gain more muscle you will also burn more calories. Typically speaking most adult females burn between 1500-2500 calories a day and most males between 2000-3000 calories per day (STUDY**). Without an energy surplus your body will need to use the calories from the food to maintain and won't have anything left to grow muscles.

\section{Protein AMOUNT and TIMING}

Ok so now we have the energy surplus thing covered, let's think about the overall protein our body has in a day. Protein is required by the body for over 300 functions e.g. speeding up chemical reactions, transporting materials around the body, muscle protein synthesis etc. If we aren't getting enough the body is probably going to use whatever protein it does have to carry out the more simple and vital functions then maintain muscle mass (given the amount isn't too low) instead of growing muscle. The recommended daily intake of protein differs between individuals based on age, weight, height, sex, activity level and training age. A guide on how much you should be aiming for is presented below.

\begin{tabular}{|l|l|}
\hline Group & $\begin{array}{l}\text { Protein intake } \\
\text { (g/kg/day) }\end{array}$ \\
\hline Sedentary men and women & $0.8-1.0$ \\
\hline Elite male and endurance athletes & 1.6 \\
\hline Moderate-intensity endurance athletes (a) & 1.2 \\
\hline Recreational endurance athletes (b) & $0.8-1.0$ \\
\hline Football, power sports & $1.4-1.7$ \\
\hline Resistance athletes (early training) & $1.5-1.7$ \\
\hline Resistance athletes (steady state) & $1.0-1.2$ \\
\hline Female athletes & $\begin{array}{l}15 \% \text { lower than } \\
\text { male athletes }\end{array}$ \\
\hline
\end{tabular}

\section{Table}

(a) Exercising approximately four to five times per week for 45-60 min

(b) Exercising four to five times per week for $30 \mathrm{~min}$ at $<55 \%$ V02peak

Source: Burke and Deakin, Clinical Sports Nutrition, 3rd Edition, McGraw-Hill Australia Pty Ltd, 2006
A study by ${ }^{* *}$ tested a group of young males who were involved in a resistance training program. One group ate $10 \mathrm{~g}$ of protein $8 \mathrm{x}$ a day, one group ate $20 \mathrm{~g}$ of protein $4 \mathrm{x}$ a day and the other ate $40 \mathrm{~g}$ twice a day. The group with greatest muscle protein synthesis aka "gains" and least amount of muscle breakdown was the group who ate $20 \mathrm{~g}$ of protein $4 \mathrm{x}$ a day. Since then, various studies have proved that eating 20-30g of protein every $3-4 \mathrm{hrs}$ is most effective for muscle building *STUDIES* Aim for $0.25 \mathrm{~g}$ *STUDY*of protein per kilo of body weight every three-four hours. For example, an $80 \mathrm{~kg}$ male would require $20 \mathrm{~g}$, which could be broken up into a meal upon waking up at $7 \mathrm{am}$ followed by meals at $11 \mathrm{am}, 3 \mathrm{pm}, 7 \mathrm{pm}$ and $11 \mathrm{pm}$. The effects of consuming $30-40 \mathrm{~g}$ of protein immediately prior to sleep have been proven beneficial for reducing the amount of time the body is in a fasting state and therefore, leads to more muscle growth.

\section{Quality of protein}

Once you figure out how much protein you should be having to cause muscle growth and how you are going to time out the protein in your day, the focus can shift to the quality of the protein source. Foods high in protein include meat, dairy, nuts, legumes and seeds. *briefly mentioned mTOR** However, recent studies suggest that the most significant muscle protein synthesis is caused by foods that contain a minimum of $2 \mathrm{~g}$ of leucine (an amino acid) within the $20-30 \mathrm{~g}$ protein amount discussed earlier. Foods high in leucine include... What this means is that you can be consuming the protein amount you need within the right time frames to keep your body in an anabolic (gaining) state but without the recommended amounts of leucine you won't be maximising your gains as much as someone who is consuming the $2 \mathrm{~g}+$ amount regularly. For example, a meal with 1 portion of salmon vs. a $250 \mathrm{~g}$ bowl of lentils might contain the same amount of protein however, there is $3500 \mathrm{mg}$ of leucine in the salmon vs. $654 \mathrm{mg}$ in the bowl of lentils. Usually the high-quality proteins are meat and dairy products however, the leucine trigger effect can occur through vegetarian/vegan sources, although it will be more difficult and will most likely require supplements or eating a really high volume of food. Meat is also much more easily absorbed by the body so be sure to use complementary proteins if using vegetarian or vegan sources of proteins. Refer to my guide on complementary proteins for assistance -> * LINK*

Micronutrients role in sleep, recovery and performance.

Something I think athletes and serious "gainers" often forget is the importance of micronutrients. I know I'm guilty of this when I think about my own attempts at growing my own "guns". Ha ha ummm ok sooo yeah we all know that as we age micronutrients are important but they're also important for helping us sleep, recover and perform better in the gym and our everyday lives for so many reasons. Just to name a few; vitamin $\mathrm{C}$ role in... 
Despite, how much you think a salad means you will waste away into nothing, don't underestimate the importance of micronutrients and the health implications for not eating them down the track...

I know that eating too much high fibre salads, fruits and vegetables can cause you to be fuller for longer with less calories which doesn't help you gain but try to incorporate vegetables where you can or find ones higher in calories like avocadoes because they are a very valuable tool to keeping you healthy and strong!

Metabolism, repairing and building.

\section{Bibliography}

1. Eugene AR and Masiak J. "The Neuroprotective Aspects of Sleep". MEDtube Science 3.1 (2015): 35-40.

2. Shokri-Kojori E., et al. " $\beta$-Amyloid accumulation in the human brain after one night of sleep deprivation". Proceedings of the National Academy of Sciences of the United States of America115 (2018): 4483-4488.

Volume 3 Issue 8 August 2019

(C) All rights are reserved by Mary-Adelle Smith. 